\title{
Motor disability in patients with multiple sclerosis: transcranial magnetic stimulation study
}

\author{
Anssam Bassem Mohy ${ }^{1}$, Aqeel Kareem Hatem ${ }^{2}$, Hussein Ghani Kadoori ${ }^{3}$ and Farqad Bader Hamdan ${ }^{3,4^{*}}$ (D)
}

\begin{abstract}
Background: Transcranial magnetic stimulation (TMS) is a non-invasive procedure used in a small targeted region of the brain via electromagnetic induction and used diagnostically to measure the connection between the central nervous system (CNS) and skeletal muscle to evaluate the damage that occurs in MS.

Objectives: The study aims to investigate whether single-pulse TMS measures differ between patients with MS and healthy controls and to consider if these measures are associated with clinical disability.

Patients and methods: Single-pulse TMS was performed in 26 patients with MS who hand an Expanded Disability Status Scale (EDSS) score between 0 and 9.5 and in 26 normal subjects. Different TMS parameters from upper and lower limbs were investigated.

Results: TMS disclosed no difference in all MEP parameters between the right and left side of the upper and lower limbs in patients with MS and controls. In all patients, TMS parameters were different from the control group. Upper limb central motor conduction time (CMCT) was prolonged in MS patients with pyramidal signs. Upper and lower limb CMCT and CMCT-f wave (CMCT-f) were prolonged in patients with ataxia. Moreover, CMCT and CMCT-f were prolonged in MS patients with EDSS of 5-9.5 as compared to those with a score of 0-4.5. EDSS correlated with upper and lower limb cortical latency (CL), CMCT, and CMCT-f whereas motor evoked potential (MEP) amplitude not.
\end{abstract}

Conclusion: TMS yields objective data to evaluate clinical disability and its parameters correlated well with EDSS.

Keywords: Multiple sclerosis, TMS, Disability, EDSS

\section{Introduction}

Multiple sclerosis (MS) is an autoimmune, progressive chronic central nervous system (CNS) disease of unknown etiology. Over time, the symptoms will get worse and more debilitating and, eventually, loss of functions will be noted often leading to substantial disability $[1,2]$.

\footnotetext{
* Correspondence: farqadbhamdan@colmed-alnahrain.edu.iq; farqadbhamdan@yahoo.com

${ }^{3}$ Department of Physiology, College of Medicine, Al-Nahrain University, Baghdad, Iraq

${ }^{4}$ Neurophysiology Unit, Al-Immamain Al-Kadhimiyain Medical City, Al-Kadhimiya, St. 60, P.O. Box 70044, Baghdad, Iraq

Full list of author information is available at the end of the article
}

The clinical disability of MS has a progressive course with eventual individual and societal impacts [3]. Several studies have demonstrated increased Expanded Disability Status Scale (EDSS) scores with time $[4,5]$ and a deterioration in the physical aspects $[5,6]$ with the progressiveness of MS.

The diagnosis of MS is primarily clinical and relies on the demonstration of symptoms and signs attributable to white matter lesions on magnetic resonance imaging (MRI). The signs and symptoms are disseminated in time (i.e., the disease course) and space (i.e., the affected areas in the CNS), along with the exclusion of other conditions that may resemble MS [7].

\section{Springer Open}

(c) The Author(s). 2020 Open Access This article is licensed under a Creative Commons Attribution 4.0 International License, which permits use, sharing, adaptation, distribution and reproduction in any medium or format, as long as you give appropriate credit to the original author(s) and the source, provide a link to the Creative Commons licence, and indicate if changes were made. The images or other third party material in this article are included in the article's Creative Commons licence, unless indicated otherwise in a credit line to the material. If material is not included in the article's Creative Commons licence and your intended use is not permitted by statutory regulation or exceeds the permitted use, you will need to obtain permission directly from the copyright holder. To view a copy of this licence, visit http://creativecommons.org/licenses/by/4.0/. 
Table 1 Baseline clinical data of patients with multiple sclerosis

\begin{tabular}{|c|c|c|c|c|c|c|c|c|}
\hline & \multirow{2}{*}{$\begin{array}{l}\text { Disease } \\
\text { duration } \\
\text { (years) }\end{array}$} & \multirow[t]{2}{*}{ EDSS } & \multicolumn{2}{|c|}{ Pyramidal sign } & \multicolumn{2}{|c|}{ Cerebellar signs } & \multicolumn{2}{|c|}{ Incoordination } \\
\hline & & & UL & LL & UL & LL & UL & LL \\
\hline 1 & 5 & 4 & + & + & - & - & + & + \\
\hline 2 & 2 & 3 & - & - & + & + & + & + \\
\hline 3 & 5 & 0 & - & - & - & - & - & - \\
\hline 4 & 18 & 3.5 & - & - & + & + & + & + \\
\hline 5 & 12 & 1 & - & - & - & - & - & - \\
\hline 6 & 5 & 1 & - & - & - & - & - & - \\
\hline 7 & 3 & 4 & + & + & + & + & + & + \\
\hline 8 & 6 & 1.5 & - & - & + & + & + & + \\
\hline 9 & 1 & 5 & + & + & + & + & - & - \\
\hline 10 & 15 & 1 & - & - & - & - & - & + \\
\hline 11 & 8 & 4.5 & - & - & - & - & + & + \\
\hline 12 & 2 & 1 & - & - & - & - & - & - \\
\hline 13 & 10 & 5 & + & + & - & - & - & - \\
\hline 14 & 19 & 3 & + & + & - & - & - & - \\
\hline 15 & 1 & 1 & + & + & - & - & - & - \\
\hline 16 & 13 & 0 & + & + & - & - & - & - \\
\hline 17 & 2 & 0 & + & + & - & - & - & - \\
\hline 18 & 3 & 1 & + & + & - & - & - & - \\
\hline 19 & 9 & 6.5 & + & + & - & + & + & + \\
\hline 20 & 1 & 2.5 & + & + & - & - & - & - \\
\hline 21 & 14 & 8 & + & + & + & - & - & - \\
\hline 22 & 7 & 7.5 & + & + & + & + & + & + \\
\hline 23 & 16 & 6.5 & + & + & - & + & + & + \\
\hline 24 & 5 & 6.5 & + & + & + & + & + & + \\
\hline 25 & 18 & 6.5 & + & + & + & + & + & + \\
\hline 26 & 20 & 6 & + & + & - & - & + & + \\
\hline 27 & 5 & 4 & + & + & - & - & + & + \\
\hline 28 & 2 & 3 & - & - & + & + & + & + \\
\hline 29 & 5 & 0 & - & - & - & - & - & - \\
\hline 30 & 18 & 3.5 & + & + & + & + & + & + \\
\hline 31 & 12 & 1 & - & - & - & - & - & - \\
\hline 32 & 5 & 1 & - & - & - & - & - & - \\
\hline 33 & 3 & 4 & - & - & + & + & + & + \\
\hline 34 & 6 & 1.5 & - & - & + & + & + & + \\
\hline 35 & 1 & 5 & + & + & - & - & - & - \\
\hline 36 & 15 & 1 & - & - & - & - & - & + \\
\hline 37 & 8 & 4.5 & + & + & - & - & + & + \\
\hline 38 & 2 & 1 & - & - & - & - & - & - \\
\hline 39 & 10 & 5 & + & + & - & - & - & - \\
\hline 40 & 19 & 3 & + & + & + & - & - & - \\
\hline 41 & 1 & 1 & - & - & - & - & - & - \\
\hline 42 & 13 & 0 & - & - & - & - & - & - \\
\hline 43 & 2 & 0 & - & - & - & - & - & - \\
\hline
\end{tabular}


Table 1 Baseline clinical data of patients with multiple sclerosis (Continued)

\begin{tabular}{|c|c|c|c|c|c|c|c|c|}
\hline & & EDSS & Pyra & & Cere & & Inco & \\
\hline & $\begin{array}{l}\text { duration } \\
\text { (years) }\end{array}$ & & UL & LL & UL & LL & UL & LL \\
\hline 44 & 3 & 1 & + & + & + & - & - & - \\
\hline 45 & 9 & 6.5 & + & + & + & + & + & + \\
\hline 46 & 1 & 2.5 & + & + & - & - & - & - \\
\hline 47 & 14 & 8 & + & + & - & - & - & - \\
\hline 48 & 7 & 7.5 & + & + & + & + & + & + \\
\hline 49 & 16 & 6.5 & + & + & + & + & + & + \\
\hline 50 & 5 & 6.5 & + & + & + & + & + & + \\
\hline 51 & 18 & 6.5 & + & + & + & + & + & + \\
\hline 52 & 20 & 6 & + & + & - & - & + & + \\
\hline
\end{tabular}

"-" indicates negative, and " + " positive

The presence or absence of dysfunction in the sensory or motor pathways in patients with MS can be ascertained by evoked potentials (EPs) especially in detecting clinically silent lesions where unclear symptoms are present. So EPs can be used as a paraclinical tool for MS evaluation $[8,9]$. These EPs are generated by stimulation of a peripheral nerve or its receptors and reflect orchestrated activity by neuronal and axonal groups in the
CNS. The motor evoked potentials (MEPs) occur when the brain's motor area is stimulated [10].

MEPs can be elicited either by transcranial electrical stimulation which is not widely used in daily clinical practice or by transcranial magnetic stimulation (TMS) technique as an alternative method. In the latter process, a high-voltage capacitor discharges into a coil of copper wire placed on the subject's head. The resulting

Table 2 TMS parameters of patients with multiple sclerosis and controls

\begin{tabular}{|c|c|c|c|c|}
\hline Parameters & & Right side & Left side & $p$ value \\
\hline \multirow[t]{2}{*}{ UL CL (ms) } & Controls & $20.18 \pm 1.84$ & $19.79 \pm 1.73$ & 0.441 \\
\hline & Patients & $24.65 \pm 3.94$ & $25.28 \pm 5.41$ & 0.604 \\
\hline \multirow[t]{2}{*}{ UL MEP amplitude (mV) } & Controls & $4.34 \pm 2.89$ & $4.03 \pm 2.81$ & 0.695 \\
\hline & Patients & $1.76 \pm 1.92$ & $1.39 \pm 1.04$ & 0.393 \\
\hline \multirow[t]{2}{*}{ UL RL (ms) } & Controls & $12.18 \pm 1.53$ & $12.28 \pm 1.4$ & 0.807 \\
\hline & Patients & $13.05 \pm 2.2$ & $12.76 \pm 1.76$ & 0.504 \\
\hline \multirow[t]{2}{*}{ UL CMCT (ms) } & Controls & $7.99 \pm 1.64$ & $7.53 \pm 1.4$ & 0.218 \\
\hline & Patients & $11.53 \pm 3.6$ & $12.2 \pm 5.0$ & 0.58 \\
\hline \multirow[t]{2}{*}{ UL CMCT-f (ms) } & Controls & $6.8 \pm 1.35$ & $6.82 \pm 1.9$ & 0.96 \\
\hline & Patients & $10.56 \pm 3.6$ & $11.23 \pm 4.82$ & 0.52 \\
\hline \multirow[t]{2}{*}{ LL CL (ms) } & Controls & $37.32 \pm 4.04$ & $37.31 \pm 3.47$ & 0.997 \\
\hline & Patients & $49.51 \pm 15.1$ & $50.51 \pm 11.04$ & 0.80 \\
\hline \multirow[t]{2}{*}{ LL MEP amplitude (mV) } & Controls & $1.13 \pm 0.23$ & $1.61 \pm 1.12$ & 0.132 \\
\hline & Patients & $0.68 \pm 0.55$ & $0.8 \pm 0.47$ & 0.432 \\
\hline \multirow[t]{2}{*}{ LL RL (ms) } & Controls & $22.34 \pm 2.95$ & $22.03 \pm 2.7$ & 0.696 \\
\hline & Patients & $24.28 \pm 4.05$ & $23.33 \pm 2.96$ & 0.364 \\
\hline \multirow[t]{2}{*}{ LL CMCT (ms) } & Controls & $14.88 \pm 3.1$ & $15.19 \pm 2.91$ & 0.714 \\
\hline & Patients & $27.4 \pm 11.44$ & $27.57 \pm 10.33$ & 0.966 \\
\hline \multirow[t]{2}{*}{ LL CMCT-f (ms) } & Controls & $12.09 \pm 2.51$ & $12.54 \pm 2.66$ & 0.534 \\
\hline & Patients & $25.51 \pm 10.69$ & $22.36 \pm 11.08$ & 0.333 \\
\hline
\end{tabular}

UL upper limb, CL cortical latency, MEP motor evoked potential amplitude, RL radicular latency, CMCT central motor conduction time, CMCT-f central motor conduction time-F, LL lower limb 
Table 3 TMS parameters of patents with multiple sclerosis and control subjects

\begin{tabular}{llll}
\hline Parameters & Patients $(\boldsymbol{n}=\mathbf{5 2})$ & Controls $(\boldsymbol{n}=\mathbf{5 2})$ & $\boldsymbol{p}$ value \\
\hline UL CL (ms) & $24.94 \pm 4.7$ & $19.98 \pm 1.78$ & $<0.001$ \\
UL MEP amplitude (mV) & $1.57 \pm 1.5$ & $1.18 \pm 2.83$ & $<0.001$ \\
UL RL (ms) & $12.91 \pm 1.98$ & $12.23 \pm 1.45$ & 0.049 \\
UL CMCT (ms) & $11.87 \pm 4.33$ & $7.76 \pm 1.53$ & $<0.001$ \\
UL CMCT-f (ms) & $10.94 \pm 4.23$ & $6.81 \pm 1.64$ & $<0.001$ \\
LL CL (ms) & $50 \pm 13.17$ & $37.31 \pm 3.73$ & $<0.001$ \\
LL MEP amplitude (mV) & $0.73 \pm 0.51$ & $1.37 \pm 1.15$ & 0.001 \\
LL RL (ms) & $23.82 \pm 3.56$ & $22.19 \pm 2.8$ & 0.012 \\
LL CMCT (ms) & $27.42 \pm 10.8$ & $15.04 \pm 2.98$ & $<0.001$ \\
LL CMCT-f (ms) & $24.0 \pm 10.87$ & $12.32 \pm 2.57$ & $<0.001$
\end{tabular}

UL upper limb, $C L$ cortical latency, MEP motor evoked potential, $R L$ radicular latency, CMCT central motor conduction time, CMCT- $f$ central motor conduction timeF, LL lower limb

magnetic field perpendicular to that coil induces an electrical current in motor neurons [11].

Even though the diagnostic relevance of EPs has been decreased after MRI which can establish an early diagnosis of the disease, they still maintain direct functional assessment of myelin, axon, and synapses in multisynaptic sensorimotor pathways, a prognostic significance and better correlate with neurological disability $[8,9,12]$. Using EP scales including MEP have a good diagnostic utility in MS and can assess neurodegeneration, predict future disability, and monitor the effects of disease-modifying drugs $[13,14]$.

Many pieces of research recommend MEPs as a useful test for predicting the clinical course of early demyelinating episodes [15], a priority for patients experiencing an initial episode of probable demyelinating disease, especially if symptoms include medullary syndrome [16], or in combination with brain MRI to confirm the diagnosis and possible clinical correlations in relapsing-remitting MS [17].

EPs have long been studied as a diagnostic and prognostic biomarker. In recent years, they were shown to help in differentiating early between possibly effective and unsuccessful interventions in phase-II trials and thus may serve as response biomarkers $[18,19]$.

In this study, we aimed to assess the motor disability using MEPs by TMS and to investigate the associations between EDSS score and MEP parameters.

\section{Methods}

A randomized prospective study was conducted at the Department of Neurophysiology/Ghazi Al-Hariri Hospital, Baghdad, Iraq, for the period from May 2019 till October 2019. The study was performed following the Declaration of Helsinki (2008) and was approved by the Iraqi Council of Medical Specialization (decision No. 1257; date, 20 March 2019). Each participant in the study ensured written informed consent.

The eligible 26 patients were ten males and 16 females (39.19 \pm 9.67 years) with a definite diagnosis of MS according to the revised McDonald criteria [20]. The duration of illness ranged from 1 year to more than 10 years. Those patients with relapsing-remitting (17 patients) and secondary progressive type (9 patients) were studied. We excluded any patient with a history of seizure, having a pacemaker, or with ferromagnetic material in the head area and other types of MS. Another 26 healthy subjects comprised of 6 males and 20 females aged $34.38 \pm 11.83$ years serve as the control group.

A thorough neurological examination and an assessment of disability status were done by a senior neurologist, including Kurtzke EDSS [21] which is used to evaluate the degree of disability of MS patients. The scale ranges from 0 (normal) to 10 (death due to MS) in 20-step scale scores (with 0.5-unit increments). EDSS

Table 4 CMCT in patients with multiple sclerosis with and without upper limb pyramidal signs, incoordination, and ataxia

\begin{tabular}{llllll}
\hline Parameters & & Number & Yes & No & \multicolumn{1}{c}{ value } \\
\hline Pyramidal signs & UL CMCT (ms) & 58 & $12.64 \pm 4.52$ & $10.89 \pm 3.96$ & 0.148 \\
& UL CMCT-f (ms) & 46 & $12.39 \pm 4.31$ & $9.12 \pm 3.42$ & $10.6 \pm 3.54$ \\
Incoordination & UL CMCT (ms) & 24 & $13.36 \pm 4.75$ & 9.005 \\
& UL CMCT-f (ms) & 26 & $12.77 \pm 4.31$ & $20.79 \pm 5.53$ & 0.020 \\
Ataxia & UL CMCT (ms) & 24 & $34.66 \pm 10.61$ & $17.62 \pm 6.2$ & $<0.003$ \\
& UL CMCT-f (ms) & 26 & $30.97 \pm 10.67$ & $<0.001$ \\
\hline
\end{tabular}

UL upper limb, CMCT central motor conduction time, CMCT-f central motor conduction time-F 
steps $1.0-4.5$ refer to fully ambulatory patients, and the precise step number is defined by the functional system score(s), while EDSS steps 5.0-9.5 are mostly described by impairment of ambulation [22].

Considering the pyramidal signs (spasticity, increased deep tendon reflex), 58 limbs with and 46 without were studied. Besides, the presence of ataxia and incoordination in upper extremities, 24 limbs with, and 26 without were examined.

A single-pulse stimulus of the cortex was delivered using a circular stimulator coil with a $90-\mathrm{mm}$ diameter (type 9784, UK) placed tangentially to the scalp (handle pointing backward) and connected to a Magstim 200 stimulator (The Magstim Company Ltd., Spring Gardens, Whitland, UK). The signals were recorded with an EMG machine (Micromed, 8-channel electromyography, $\mathrm{B}$, model 1715 , Italy) from the abductor pollicis brevis (APB) in the upper limbs and the tibialis anterior (TA) in the lower limbs by disk surface electrodes in a belly-tendon montage.

Patients were seated comfortably with the arms at rest. The stimulus was delivered at intensity approximately 15-20\% above threshold until at least two reproducible responses were obtained to reduce the variability. MEPs with the shortest latency and largest amplitude were evaluated. The filter setting used was $30-\mathrm{Hz}$ low filter and $30-\mathrm{kHz}$ high filter. The coil center positioned over or slightly anterior to the vertex for cortical stimulation of upper or lower limbs, respectively. For the spinal roots, the magnetic stimulation was done by placing the center of the circular coil over the 7th cervical and 5th lumbar vertebrae.

The parameters evaluated were the following: cortical$\mathrm{APB} / \mathrm{TA}$ latencies (CL) and spinal cord (cervical/LS spine)-APB/TA latencies correspond to radicular latency (RL); MEP amplitude from peak to baseline; central motor conduction time (CMCT); and central motor conduction time-f wave (CMCT-f). The CMCT was measured by subtracting the latency resulting from spinal stimulation from that on cortical stimulation. CMCT-f was measured with the following equation:

$$
\mathrm{CMCT}-\mathrm{f}(\mathrm{ms})=\frac{\mathrm{TMCT}-(\mathrm{F} \min .+\mathrm{DML})-1}{2}
$$

where CMCT-f $=$ central motor conduction time using $\mathrm{F}$ wave latency, $\mathrm{TMCT}=$ total motor conduction time (cortical latency), $\mathrm{F}$ min. $=$ minimum $\mathrm{F}$ wave latency, and $\mathrm{DML}=$ distal motor latency [23]

\section{Statistical analysis}

Statistical analysis was performed using IBM-SPSS (Statistical Package for Social Sciences) version 25 (IBM incorporation, USA). Normal distribution of the
Table 5 CMCT in patients with multiple sclerosis with different EDSS

\begin{tabular}{|c|c|c|c|}
\hline \multirow[t]{2}{*}{ Parameters } & \multicolumn{2}{|l|}{ EDSS } & \multirow{2}{*}{$\begin{array}{l}p \\
\text { value }\end{array}$} \\
\hline & $0-4.5(n=32)$ & $5-9.5(n=20)$ & \\
\hline$\overline{U L C M C T}$ (ms) & $10.87 \pm 3.88$ & $13.47 \pm 4.62$ & 0.034 \\
\hline UL CMCT-f (ms) & $9.68 \pm 3.75$ & $12.96 \pm 4.26$ & 0.005 \\
\hline LL CMCT (ms) & $24.7 \pm 9.49$ & $33.74 \pm 11.35$ & 0.007 \\
\hline LL CMCT-f (ms) & $21.1 \pm 9.45$ & $30.64 \pm 11.32$ & 0.005 \\
\hline
\end{tabular}

EDSS expanded disability status scale, UL upper limb, CMCT central motor conduction time, CMCT-f central motor conduction time-F, LL lower limb

data was assessed with the Kolmogorov-Smirnov test, and variance homogeneity was evaluated with the Levene test. Pearson correlation coefficient was used to analyze the relationship between EDSS and MEP parameters.

An independent $t$ test was used to analyze the difference between right and left side in the control group and MS patients and between controls and MS patients concerning MEP parameters and clinical data. A $p$ value of $\leq 0.05$ was considered significant.

\section{Results}

The pyramidal and cerebellar signs and incoordination in the upper and lower limbs, disease duration, and EDSS for all patients with MS were presented in Table 1.

MEPs were elicited in all the four limbs in controls and patients with MS. In both groups, no significant difference was demonstrated between the right and left side of the upper and lower limbs considering all MEP parameters (Table 2). Thus, they were tabulated as one group for the upper limbs and another one for the lower limbs for further statistics.

The upper limb and lower limb CL, RL, CMCT, CMCT-f, and upper limb MEP amplitude were significantly higher in patients with MS. In contrast, the lower limb MEP amplitude was significantly lower in patients with MS when compared to the control group (Table 3).

Table 6 Correlation of CMCT and CMCT-f with disease duration

\begin{tabular}{lll}
\hline Parameters & Disease duration & \\
\cline { 2 - 3 } & Correlation coefficient & $\boldsymbol{p}$ value \\
\hline UL CMCT (ms) & 0.092 & 0.515 \\
UL CMCT-f (ms) & 0.044 & 0.756 \\
LL CMCT (ms) & 0.097 & 0.522 \\
LL CMCT-f (ms) & 0.078 & 0.606 \\
\hline
\end{tabular}

UL upper limb, CMCT central motor conduction time, CMCT-f central motor conduction time with F wave, LL lower limb 

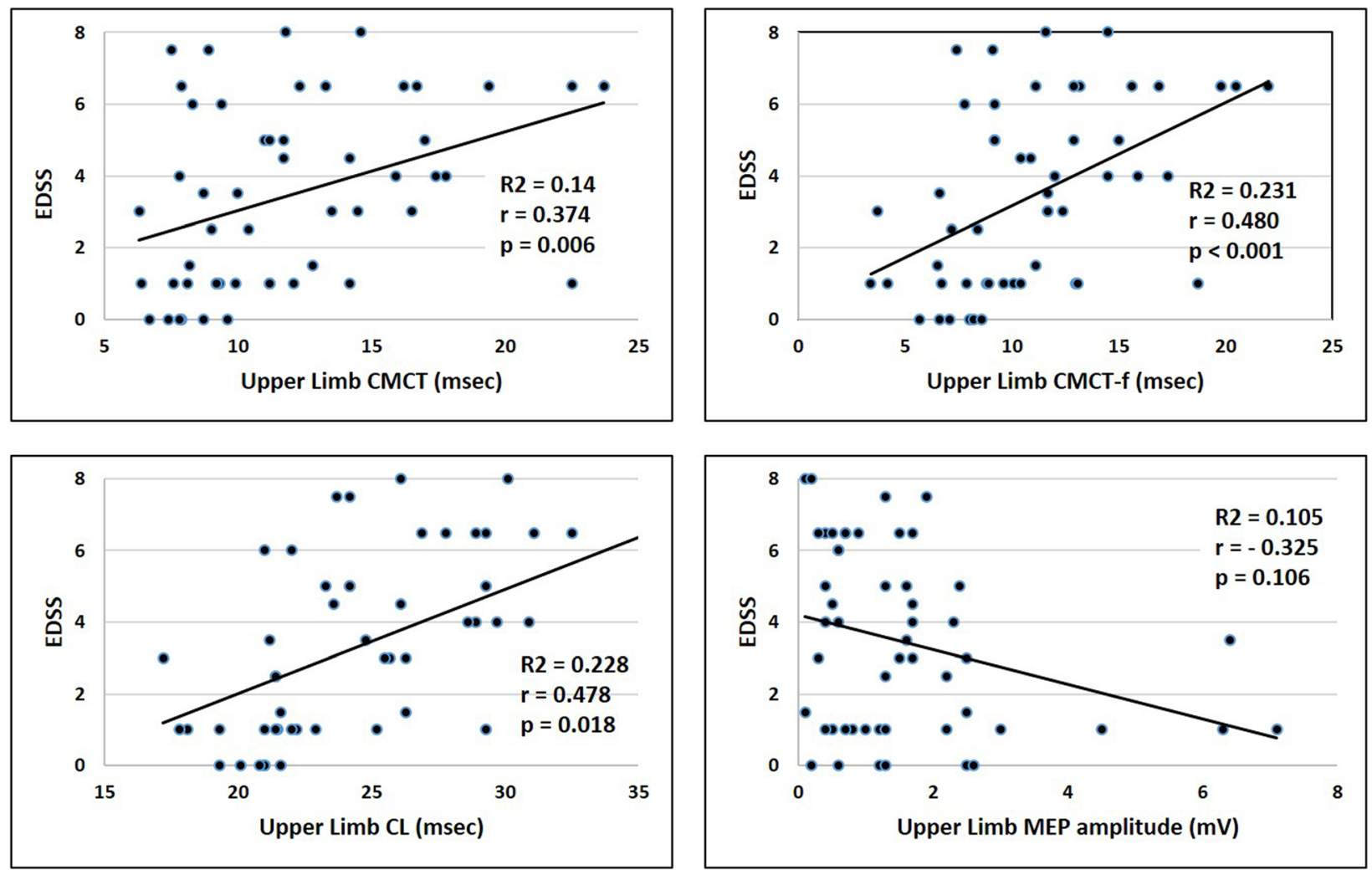

Fig. 1 Relationship of EDSS and upper limb CMCT (upper left), CMCT-f (upper right), CL (lower left), and MEP amplitude (lower right)

Table 4 illustrates that the upper limb CMCT was the only parameter that is significantly prolonged $(p=0.005)$ in patients with pyramidal signs $(12.39 \pm 4.31 \mathrm{~ms})$ as compared to patients without $(9.12 \pm 3.42 \mathrm{~ms})$. Also, upper limb CMCT and CMCT-f were significantly prolonged in those patients with ataxia and incoordination.

Upper and lower limb CMCT and CMCT-f were significantly prolonged in those patients with EDSS of 5-9.5 as compared to those with a score of 0-4.5 (Table 5).

Table 6 illustrated no significant correlation between either CMCT or CMCT-f and the duration of disease in MS patients.

In the upper limb, a significant positive correlation was observed between EDSS and CL $(r=0.636, p<0.001)$, EDSS and CMCT $(r=0.374, p=0.006)$, and EDSS and CMCT-f $(r=0.480, p<0.001)$. On the contrary, a nonsignificant negative correlation was observed between EDSS and MEP amplitude $(r=-0.325, p=0.106)$ as shown in Fig. 1.

Similarly, in the lower limb, a significant positive correlation was observed between EDSS and CL $(r=0.478, p=$ $0.018)$, EDSS and CMCT $(r=0.588, p<0.001)$, and EDSS and CMCT-f $(r=0.553, p<0.001)$. On the reverse, a nonsignificant negative correlation was observed between
EDSS and MEP amplitude $(r=-0.397, p=0.067)$ as shown in Fig. 2.

\section{Discussion}

In our study, both the healthy controls and patients with MS showed no hemispheric difference. Caramia et al. [24], Neva et al. [25], and Zipser et al. [26] also demonstrated such findings but with contradictory results which could be due to the sample size difference, stimulus, and stimulation coil types.

TMS of our patients with MS revealed abnormal corticospinal excitability which could be due to central or peripheral neuronal demyelination or to peripheral corticospinal axonal damage. Neva et al. [25], Gagliardo et al. [27], Udupa and Chen [28], Bridoux et al. [29], Conte et al. [30], Nantes et al. [31], and Nantes et al. [32] relate this hyperexcitability to neuronal demyelination. On the contrary, Ziemann et al. [9], Groppa et al. [33], and Simpson and Macdonell [34] demonstrate axonal damage of corticospinal tracts as a cause for the hyperexcitability of patients with MS.

MEP amplitude variability between the upper and lower limbs in this study could be explained by that the motor thresholds vary according to the muscle being assessed. Fernández et al. [10] denoted that thresholds 

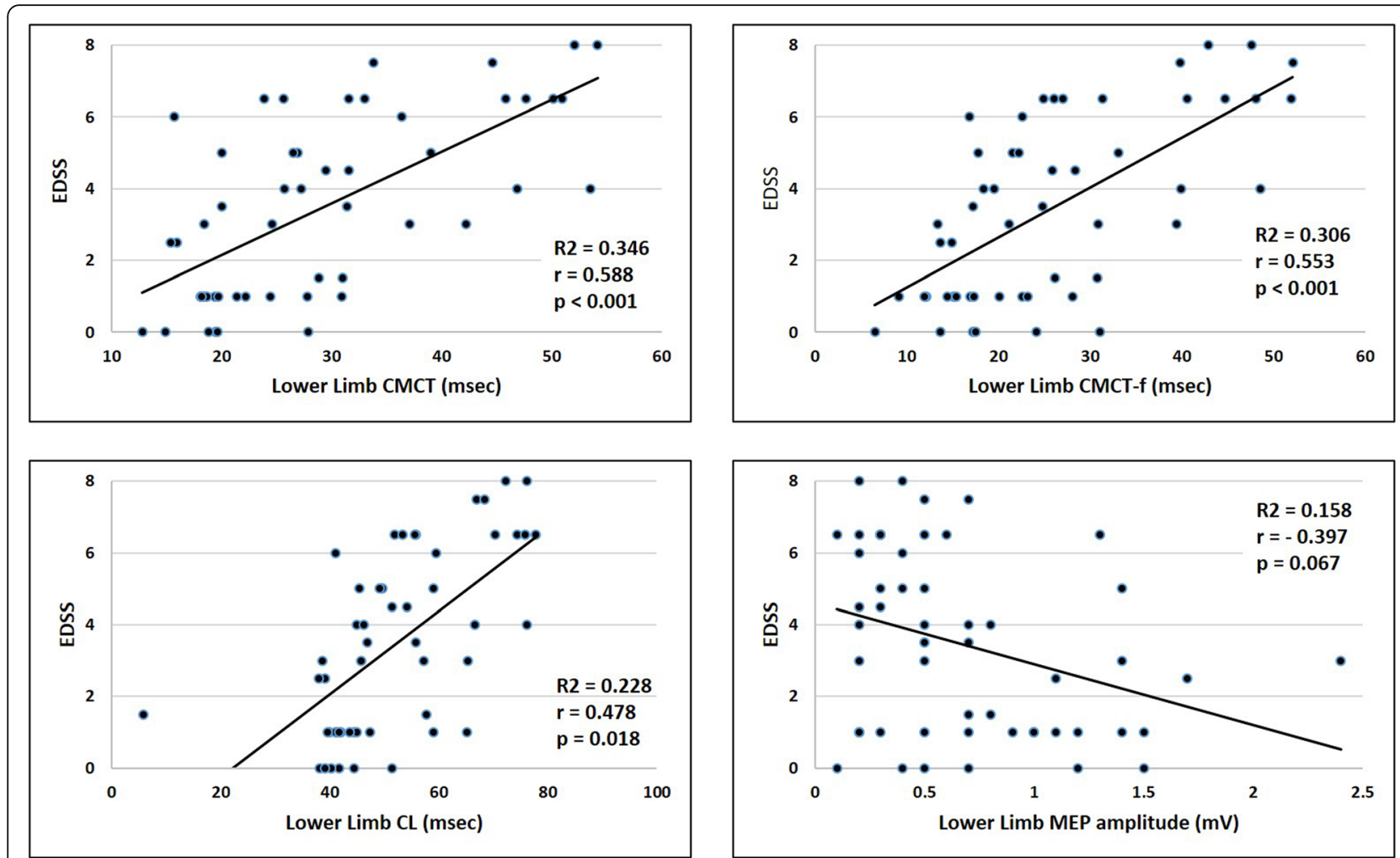

Fig. 2 Relationship of EDSS and lower limb CMCT (upper left), CMCT-f (upper right), CL (lower left), and MEP amplitude (lower right)

are lower for hand muscles than for axial muscles or proximal muscles of the arms or legs. Furthermore, MEP amplitude depends on several factors, including coil position, subject's attention, and tonic facilitation of the muscle in question. Thus, this measurement has little value in clinical practice.

Our patients with MS who have a clinical picture of incoordination, ataxia, and pyramidal signs demonstrate typical CMCT and CMCT-f abnormalities. CMC abnormality was known to be closely correlated with clinical signs of upper motor neuron disturbance, and the Babinski sign when measured from LL [35-37].

EDSS of the present study is well correlated with CL, CMCT, and CMCT-f but not with MEP amplitude. Zeller et al. [38], Vucic et al. [39], and Schlaeger et al. [40] found the same results. On the contrary, Neva et al. [25] found no relationship between CL and EDSS. A potential explanation for that as they proposed is that their work only included patients with relapsing-remitting MS. In contrast, previous studies included individuals with relapsing-remitting MS as well as individuals with primary and secondary progressive MS. Moreover, Sahota et al. [37] demonstrate a lack of correlation between EDSS and CMCT abnormalities. On the other hand, Zeller et al. [38], Schlaeger et al. [40], and Kale et al. [41] found EDSS to be negatively related to MEP amplitude.
EDSS is a standard measure to assess motor, sensory, and cognitive disability levels and is informative as a measure of neurological impairment and MS progression. An increased disability may indicate that the neurons are spastially farther away from the central target muscle representation. Besides, intrinsically less excitable neurons have a greater degree of dysfunction because of advanced cortical damage and demyelination of corticospinal output. These data provide further insights into the potential neural dysfunction associated with clinical disability in MS. Generally, such abnormalities might be due to abnormal propagation of central or peripheral neural signals throughout the corticospinal system $[42,43]$.

\section{Conclusion}

TMS yields objective data to monitor clinical disability in patients with MS, owing to the significant correlation observed between the abnormalities in CMCT and the degree of motor disability. MEP latency and CMCT have the most evidence for use as biomarkers in the clinical approach to MS. To further correlate MEP parameters with EDSS of patients with MS following drug monitoring disease progression, extensive prospective serial studies are required. 


\section{Abbreviations}

APB: Abductor pollicis brevis; CL: Cortical latency; CMCT: Central motor conduction time; CNS: Central nervous system; EDSS: Expanded Disability Status Scale; EPs: Evoked potentials; MEPs: Motor EPs; MRI: Magnetic resonance imaging; MS: Multiple sclerosis; RL: Radicular latency; TA: Tibialis anterior; TMS: Tanscranial magnetic stimulation

\section{Acknowledgements}

We thank assistant professor Dr. Qasim S. Al-Mayah (Research Medical Unit, College of Medicine, Al-Nahrain University) for doing the statistical analysis.

\section{Settings}

Department of Neurophysiology/Ghazi Al-Hariri Hospital, Baghdad, Iraq

\section{Authors' contributions}

Concept-FBH and AKH. Design-ABM and HGK. Supervision-FBH and AKH. Resources-ABM and HGK. Materials - AMB and AKH. Data collection and/or processing- $\mathrm{FBH}$ and $\mathrm{HGK}$. Analysis and/or interpretation- $\mathrm{FBH}$ and $\mathrm{ABM}$. Literature search-ABM and FBH. Writing manuscript-FBH and HGK. All authors have read and approved the manuscript.

\section{Funding}

Self-funding.

\section{Availability of data and materials}

All data generated or analyzed during this study are included in this published article. The datasets used and/or analyzed during the current study are available from the corresponding author on reasonable request.

\section{Ethics approval and consent to participate}

The study design was approved by the Iraqi Council of Medical Specialization (decision No. 1257; date, 20 March 2019).

\section{Consent for publication}

Not applicable.

\section{Competing interests}

The authors declare that they have no competing interest.

\section{Author details}

${ }^{1}$ Neurophysiology Unit, Al-Wasity Hospital, Al-Risafa Health Directorate, Ministry of Health, Baghdad, Iraq. ${ }^{2}$ Section of Neurology, Department of Medicine, Faculty of Medicine, Baghdad University, Baghdad, Iraq. ${ }^{3}$ Department of Physiology, College of Medicine, Al-Nahrain University, Baghdad, Iraq. ${ }^{4}$ Neurophysiology Unit, Al-Immamain Al-Kadhimiyain Medical City, Al-Kadhimiya, St. 60, P.O. Box 70044, Baghdad, Iraq.

Received: 30 June 2020 Accepted: 26 November 2020 Published online: 09 December 2020

\section{References}

1. Dendrou CA, Fugger L, Friese MA. Immunopathology of multiple sclerosis. Nat Rev Immunol. 2015;15:545-58.

2. Nasios G, Messinis L, Dardiotis E, Papathanasopoulos P. Repetitive transcranial magnetic stimulation, cognition, and multiple sclerosis: an overview. Behav Neurol. 2018;2018:Article ID 8584653.

3. Pugliatti M, Rosati G, Carton H, Riise T, Drulovic J, Vecsei L, et al. The epidemiology of multiple sclerosis in Europe. Eur J Neurol. 2006;13:700-22.

4. Chruzander C, Johansson S, Gottberg K, Einarsson U, Fredrikson S, Holmqvist LW, et al. A 10-year follow-up of a population-based study of people with multiple sclerosis in Stockholm, Sweden: changes in disability and the value of different factors in predicting disability and mortality. J Neurol Sci. 2013; 332:121-7.

5. Tepavcevic DK, Pekmezovic T, Stojsavljevic N, Kostic J, Basuroski ID, Mesaros $S$, et al. Change in quality of life and predictors of change among patients with multiple sclerosis: a prospective cohort study. Qual Life Res. 2014;23: 1027-37.

6. Chruzander C, Ytterberg C, Gottberg K, Einarsson U, Holmqvist LW, Johansson S. A 10-year follow-up of a population-based study of people with multiple sclerosis in Stockholm, Sweden: changes in health-related quality of life and the value of different factors in predicting health-related quality of life. J Neurol Sci. 2014;339:57-63.

7. Miller DH, Weinshenker BG, Filippi M, Banwell BL, Cohen JA, Freedman MS, et al. Differential diagnosis of suspected multiple sclerosis: a consensus approach. Mult Scler. 2008;14:1157-74.

8. Chen R, Cros D, Curra A, Di Lazzaro V, Lefaucheur JP, Magistris MR, et al. The clinical diagnostic utility of transcranial magnetic stimulation: report of an IFCN committee. Clin Neurophysiol. 2008;119:504-32.

9. Ziemann $U$, Wahl M, Hattingen E, Tumani H. Development of biomarkers for multiple sclerosis as a neurodegenerative disorder. Prog Neurobiol. 2011;95: 670-85

10. Valls-Sole J, Relova JL, Raguer N, Miralles F, Dinca L, et al. Recommendations for the clinical use of motor evoked potentials in multiple sclerosis. Neurología. 2013;28:408-16.

11. Hallett M. Transcranial magnetic stimulation: a primer. Neuron. 2007:55:187-99.

12. Jung P, Beyerle A, Ziemann U. Multimodal evoked potentials measure and predict disability progression in early relapsing-remitting multiple sclerosis. Mult Scler. 2008;14:553-6.

13. Schlaeger R, D'Souza M, Schindler C, Grize L, Dellas S, Radue EW, et al. Prediction of long-term disability in multiple sclerosis. Mult Scler. 2012;18:31-8.

14. Schlaeger R, D'Souza M, Schindler C, Grize L, Kappos L, Fuhr P. Combined evoked potentials as markers and predictors of disability in early multiple sclerosis. Clin Neurophysiol. 2012;123:406-10.

15. Pallix-Guyot M, Guennoc AM, Blasco H, de Toffol B, Corcia P, Praline J. Predictive value of motor evoked potentials in clinically isolated syndrome. Acta Neurol Scand. 2011;124:410-6.

16. Gajofatto A, Monaco S, Fiorini M, Zanusso G, Vedovello M, Rossi F, et al. Assessment of outcome predictors in first-episode acute myelitis: a retrospective study of 53 cases. Arch Neurol. 2010;67:724-30.

17. Bejarano B, Bianco M, Gonzalez-Moron D, Sepulcre J, Goñi J, Arcocha J, et al. Computational classifiers for predicting the short-term course of multiple sclerosis. BMC Neurol. 2011:11:67.

18. Iodice R, Carotenuto A, Dubbioso R, Cerillo I, Santoro L, Manganelli F. Multimodal evoked potentials follow up in multiple sclerosis patients under fingolimod therapy. J Neurol Sci. 2016;365:143-6.

19. Hardmeier M, Leocani L, Fuhr P. A new role for evoked potentials in MS? Repurposing evoked potentials as biomarkers for clinical trials in MS. Mult Scler. 2017:23:1309-19.

20. Thompson AJ, Banwell BL, Barkhof F, Carroll WM, Coetzee T, Comi G, et al Diagnosis of multiple sclerosis: 2017 revisions of the McDonald criteria. Lancet Neurol. 2018;17:162-73.

21. Kurtzke JF. Rating neurologic impairment in multiple sclerosis: an expanded disability status scale (EDSS). Neurology. 1983;33:1444-52.

22. Hatipoglu H, Kabay SC, Hatipoglu MG, Ozden H. Expanded Disability Status Scale-based disability and dental-periodontal conditions in patients with multiple sclerosis. Med Princ Pract. 2016;25:49-55.

23. Kimura J. Motor evoked potentials. In: Electrodiagnosis in diseases of nerve and muscle, Chapter 20. 4th ed. New York: Oxford University Press; 2013. p. $525-72$.

24. Caramia MD, Palmieri MG, Desiato MT, Boffa L, Galizia P, Rossini PM, et al. Brain excitability changes in the relapsing and remitting phases of multiple sclerosis: a study with transcranial magnetic stimulation. Clin Neurophysiol. 2004:115:956-65.

25. Neva JL, Lakhani B, Brown KE, Wadden KP, Mang CS, Ledwell NHM, et al. Multiple measures of corticospinal excitability are associated with clinical features of multiple sclerosis. Behav Brain Res. 2016;297:187-95.

26. Zipser CM, Premoli I, Belardinelli P, Castellanos N, Rivolta D, Heidegger T, et al. Cortical excitability and interhemispheric connectivity in early relapsing-remitting multiple sclerosis studied with TMS-EEG. Front Neurosci. 2018:12:393

27. Gagliardo A, Galli F, Grippo A. Motor evoked potentials in multiple sclerosis patients without walking limitation: amplitude vs conduction time abnormalities. J Neurol. 2007;254:220-7

28. Udupa K, Chen R. Central motor conduction time. Handb Clin Neurol. 2013; 116:375-86

29. Bridoux A, Creange A, Sangare A, Ayache SS, Hosseini H, Drouot X, et al. Impaired sleep-associated modulation of post-exercise corticomotor depression in multiple sclerosis. J Neurol Sci. 2015:354:91-6.

30. Conte A, Li Voti P, Pontecorvo S, Quartuccio ME, Baione V, Rocchi L, et al. Attention-related changes in short-term cortical plasticity help to explain fatigue in multiple sclerosis. Mult Scler J. 2016;22:1359-66. 
31. Nantes JC, Zhong J, Holmes SA, Whatley B, Narayanan S, Lapierre Y, et al. Intracortical inhibition abnormality during the remission phase of multiple sclerosis is related to upper limb dexterity and lesions. Clin Neurophysiol. 2016;127:1503-11.

32. Nantes JC, Zhong J, Holmes SA, Narayanan S, Lapierre Y, Koski L. Cortical damage and disability in multiple sclerosis: relation to intracortical inhibition and facilitation. Brain Stimul. 2016;9:566-73.

33. Groppa S, Oliviero A, Eisen A, Quartarone A, Cohen LG, Mall V, et al. A practical guide to diagnostic transcranial magnetic stimulation: report of an IFCN committee. Clin Neurophysiol. 2012;123:858-82.

34. Simpson M, Macdonell $R$. The use of transcranial magnetic stimulation in diagnosis, prognostication and treatment evaluation in multiple sclerosis. Mult Scler Relat Disord. 2015:4:430-6.

35. Kidd D, Thompson PD, Day BL, Rothwell JC, Kendall BE, Thompson AJ, et al. Central motor conduction time in progressive multiple sclerosis. Correlations with MRI and disease activity. Brain. 1998;121:1109-16.

36. Cruz-Martinez A, Gonzalez-Orodea Jl, Lopez PR, Arpa J. Disability in multiple sclerosis. The role of transcranial magnetic stimulation. Electromyogr Clin Neurophysiol. 2000;40:441-7.

37. Sahota P, Prabhakar S, Lal V, Khurana D, Das CP, Singh P. Transcranial magnetic stimulation: role in the evaluation of disability in multiple sclerosis. Neurol India. 2005;53:197-201.

38. Zeller D, Kampe K, Biller A, Stefan K, Gentner R, Schütz A, et al. Rapid-onset central motor plasticity in multiple sclerosis. Neurology. 2010;74:728-35.

39. Vucic S, Burke T, Lenton K, Ramanathan S, Gomes L, Yannikas C, et al. Cortical dysfunction underlies disability in multiple sclerosis. Mult Scler J. 2012;18:425-32.

40. Schlaeger R, Hardmeier M, D'Souza M, Grize L, Schindler C, Kappos L, et al. Monitoring multiple sclerosis by multimodal evoked potentials: numerically versus ordinally scaled scoring systems. Clin Neurophysiol. 2016;127:1864-71.

41. Kale N, Agaoglu J, Tanik O. Electrophysiological and clinical correlates of corpus callosum atrophy in patients with multiple sclerosis. Neurol Res. 2010;32:886-90.

42. Tataroglu C, Genc A, Idiman E, Cakmur R, Idiman F. Cortical silent period and motor evoked potentials in patients with multiple sclerosis. Clin Neurol Neurosurg. 2003;105:105-10.

43. Mori F, Kusayanagi H, Monteleone F, Moscatelli A, Nicoletti CG, Bernardi G, et al. Short interval intracortical facilitation correlates with the degree of disability in multiple sclerosis. Brain Stimul. 2013;6:67-71.

\section{Publisher's Note}

Springer Nature remains neutral with regard to jurisdictional claims in published maps and institutional affiliations.

\section{Submit your manuscript to a SpringerOpen ${ }^{\circ}$ journal and benefit from:}

- Convenient online submission

- Rigorous peer review

- Open access: articles freely available online

- High visibility within the field

- Retaining the copyright to your article

Submit your next manuscript at $\boldsymbol{\nabla}$ springeropen.com 